\title{
Optimization of Fermentation Process Enhancing Quality of Dandelion Black Tea on the Functional Components, Activity and Sensory Quality
}

\author{
Yaru Ning ${ }^{*}$, Zhe Wu ${ }^{2 *}$, Zhaojia Li1,3, Ran Meng1,3, Zhizhong Xue ${ }^{1,3}$, Xiuping Wang ${ }^{1,3}$, Xuelin Lu ${ }^{1,3}$, \\ Xiaodong Zhang1\# \\ ${ }^{1}$ Institute of Coastal Agriculture, Hebei Academy of Agriculture and Forestry Sciences, Tangshan, China \\ ${ }^{2}$ Saline-Alkali Land Greening Technology Innovation Center of Hebei Province, Tangshan, China \\ ${ }^{3}$ Tangshan Key Laboratory of Plant Salt-Tolerance Research, Tangshan, China \\ Email: " wuzhe26@163.com
}

How to cite this paper: Ning, Y.R., Wu, Z., Li, Z.J., Meng, R., Xue, Z.Z., Wang, X.P., Lu, X.L. and Zhang, X.D. (2020) Optimization of Fermentation Process Enhancing Quality of Dandelion Black Tea on the Functional Components, Activity and Sensory Quality. Open Access Library Journal, 7: e6323. https://doi.org/10.4236/oalib.1106323

Received: April 14, 2020

Accepted: April 27, 2020

Published: April 30, 2020

Copyright $\odot 2020$ by author(s) and Open Access Library Inc.

This work is licensed under the Creative Commons Attribution International License (CC BY 4.0).

http://creativecommons.org/licenses/by/4.0/

\begin{abstract}
The fermentation technology of dandelion black tea was optimized by Box-Behnken response surface method. Combined with sensory evaluation and biochemical analysis, the effects of fermentation conditions such as temperature, time and humidity on the functional components, sensory quality and antioxidant function of dandelion black tea were evaluated. Results showed that under the conditions of fermentation temperature of $25^{\circ} \mathrm{C}$, humidity of $80 \%$ and time of $15 \mathrm{~h}$, functional properties of dandelion black tea were the highest, of which, chlorogenic acid was $1.53 \mathrm{mg} / \mathrm{g}$, water extracts of tea were $32.59 \%$, tea polyphenol was $1.535 \%$, DPPH radical scavenging rate was $95.9 \%$, and tea soup had good sensory quality, orange and mellow taste. Various volatile flavor components among different fermentation treatments with the maximum difference of $45.3 \%$ were found, including 17 alcohols, 14 aldehydes, 12 ketones, 6 esters, 6 organic acids, 5 sulfur compounds, indicating that optimized fermentation process could change the types and quantity of volatile compounds, thus affecting sensory quality of dandelion black tea. This study could provide a reference for the development of high-quality functional dandelion black tea.
\end{abstract}

\section{Subject Areas}

Biotechnology, Food Science \& Technology

${ }^{\star}$ Co-authors contribute equally. 


\section{Keywords}

Dandelion Black Tea, Fermentation Process, Biochemical Composition, Aroma Components, Antioxidant Activity

\section{Introduction}

Dandelion (Taraxacum mongolicum Hand.-Mazz.) is a kind of perennial herb and can be used as both food and medicine. It contains many active ingredients such as phenolic acids, organic acids, polysaccharides, flavonoids, etc. Its taste is slightly bitter, and functions as detoxification, bacteriostasis, detumescence, anti-inflammatory, anti-oxidation, reducing cholesterol, lowering blood sugar and anti-thrombosis, etc. [1].

With the improvement of focus on human health, dandelion has been developed into a variety of functional foods, such as dandelion black tea, a main dandelion product which is suitable for convenient drinking. Black tea is one of the six major types of tea in China with characteristics of red liquid, red soup and sweet-mellow taste [2]. The taste substances and functional components of black tea include tea polyphenols, tea pigments, amino acids, tea extracts, etc. [3]. Most of tea polyphenols belong to flavonoid compounds and their derivatives, which are the key substances to determine the taste and color of black tea infusion. Different content and proportion of polyphenols form different unique taste characteristics of black tea, and it also has a strong antioxidant capacity and a certain role in delaying aging [4]; Black tea pigment is a kind of polyphenols extracted from black tea soup and the main components are water-soluble pigments like theaflavins, thearubigins and theabrownins, which have an important impact on the function and quality of black tea [2] [3].

Black tea processing technology mainly includes withering, rolling, fermentation and drying [4] [5]. The process can remove the bitterness of dandelion, improve the flavor quality of dandelion tea, and make up for the defect of cold property of dandelion [6]. Hence, dandelion black tea is suitable for a wider range of people to drink. However, quality of dandelion black tea on the market at present is different, and there are great flavor quality problems, for example the tea shape is not tightly rolled, and the tea soup is dark and bitter, etc. In order to solve the quality problems of dandelion black tea and improve the efficacy of the product, the current study optimized the fermentation process of the key technology of dandelion black tea processing, in order to enhance the sensory quality and activity of functional components in dandelion black tea.

\section{Materials and Methods}

\subsection{Materials}

The raw material of dandelion black tea was taken from the fresh leaves of 
"Binpu No. 1", a new dandelion variety developed by Institute of Coastal Research, Hebei Academy of Agriculture and Forestry Sciences (Figure 1).

\subsection{Dandelion Black Tea Processing Technology}

The fresh dandelion leaves were spread out in a thin layer and naturally dried 24 $\mathrm{h}$ in ventilated room, then transferred into a fermenter. The fermentation temperature, humidity and time were optimized by the Box-Behnken response surface methodology and details were shown in Table 1.

The fermented dandelion was baked and fried at $190^{\circ} \mathrm{C}$ for $15 \mathrm{~min}$, and then checked the contents of caffeic acid, chlorogenic acid, tea pigments, tea polyphenols, tea water extracts and aroma components.
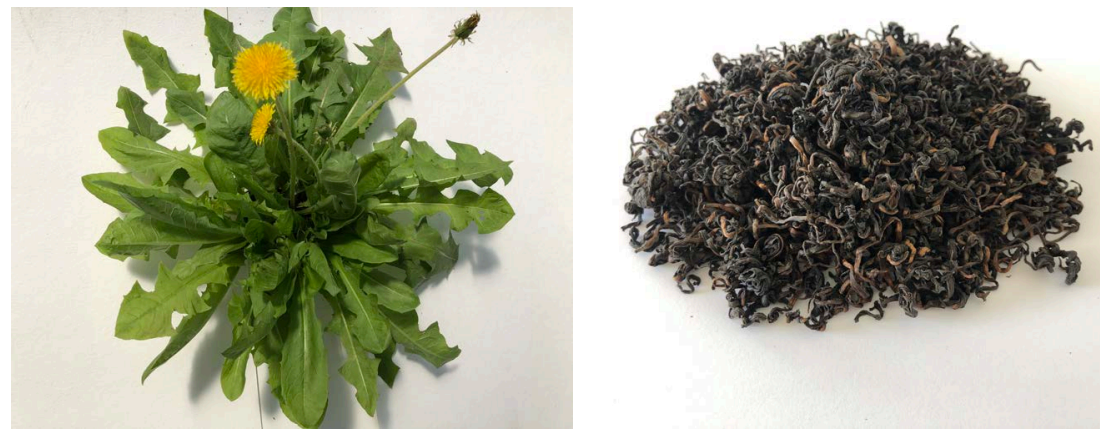

Figure 1. Dandelion cultivar "Binpu No. 1" and its black tea product.

Table 1. Box-Behnken optimization design for temperature, humidity and time.

\begin{tabular}{|c|c|c|c|}
\hline No. & Temperature $\left({ }^{\circ} \mathrm{C}\right)$ & Humidity (\%) & Time (h) \\
\hline 1 & 40 & 70 & 22.5 \\
\hline 2 & 40 & 90 & 22.5 \\
\hline 3 & 40 & 80 & 30 \\
\hline 4 & 40 & 80 & 15 \\
\hline 5 & 32.5 & 80 & 22.5 \\
\hline 6 & 32.5 & 90 & 15 \\
\hline 7 & 32.5 & 90 & 30 \\
\hline 8 & 32.5 & 70 & 15 \\
\hline 9 & 32.5 & 70 & 30 \\
\hline 10 & 25 & 90 & 22.5 \\
\hline 11 & 25 & 80 & 30 \\
\hline 12 & 25 & 80 & 15 \\
\hline 13 & 25 & 70 & 22.5 \\
\hline
\end{tabular}




\subsection{Sensory Evaluation}

Sensory quality of the dandelion black tea was evaluated according to the black tea evaluation method described in China national technology standard (GB/T 23776-2018) [7]; the testers conduct sensory evaluation on the shape, liquid color, aroma, taste and leaf base of the samples, with 100 scores for each item, and the total sensory score $=$ shape $\times 25 \%+$ liquid color $\times 10 \%+$ aroma $\times 25 \%+$ taste $\times 30 \%+$ leaf base $\times 10 \%$.

\subsection{Determine Methods for Chemical Components in Dandelion Black Tea}

Tea color variation. Dandelion tea of $0.357 \mathrm{~g}$ was directly added $150 \mathrm{ml}$ boiling water, standing for $5 \mathrm{~min}$, and then read the optical density (OD) at $380 \mathrm{~nm}$ from ultraviolet spectrophotometer after filtered through $0.45 \mu \mathrm{m}$ membrane. The distilled water was as blank, and tea color variation was described as the relative change of $O D$ value.

Phenolic acid compound examination. Dandelion tea sample of $0.0833 \mathrm{~g}$ mixed with $5 \mathrm{ml} 0.1 \%$ cellulase solution was incubated at $60^{\circ} \mathrm{C}$ for $30 \mathrm{~min}$, then added $70 \%$ methanol solution to $25 \mathrm{ml}$ and then ultrasonic processed for 120 $\min$ at $120 \mathrm{~W}$ and $60^{\circ} \mathrm{C}$. The extraction solution was filtered through $0.45 \mu \mathrm{m}$ membrane for phenolic acid compound examination by an Agilent 1200 HPLC (Agilent Technologies Inc., USA) equipped with Diamonsil $\mathrm{C}_{18}$ column $(4.6 \mathrm{~mm}$ $\times 250 \mathrm{~mm}, 5 \mu \mathrm{m}$, Dikma Technologies Inc., China). Column temperature was $35^{\circ} \mathrm{C}$, flow rate $1 \mathrm{ml} / \mathrm{min}$ and sampling rate $10 \mu \mathrm{l}$. Mobile phase of A (methanol): B $(0.02 \%$ phosphate buffer) was $50: 50$ and read at $350 \mathrm{~nm}$.

Dry matter weight, tea polyphenols and water extract content were examined by the methods described in China national technology standards (GB/T 8304-2013, GB/T8313-2018 and GB/T8305-2013) [7].

Analysis of aroma components in dandelion black tea. The $5 \mathrm{~g}$ dandelion tea sample was incubated in headspace sampling bottles. The volatile components were detected by GC-IMS and analyzed by Flavour Spec gas phase ion mobility spectrometer (G.A.S. Inc., Germany) [8]. The detection conditions of GC-IMS were modified as follows: headspace incubation temperature $80^{\circ} \mathrm{C}$, incubation time $20 \mathrm{~min}$, incubation speed $500 \mathrm{rpm}$. The carrier gas was nitrogen, the column temperature was $60^{\circ} \mathrm{C}$, the chromatographic running time was $30 \mathrm{~min}$, the flow rate gradient of the carrier gas was set at $2 \mathrm{ml} / \mathrm{min}$, maintained for $2 \mathrm{~min}$, and linearly increased to $10 \mathrm{ml} / \mathrm{min}$ within $10 \mathrm{~min}$, to $100 \mathrm{ml}$ within $20 \mathrm{~min}$ and to $150 \mathrm{ml} / \mathrm{min}$ within $30 \mathrm{~min}$. The temperature of the injection needle was $85^{\circ} \mathrm{C}$ and the injection volume was $500 \mu \mathrm{L}$.

Antioxidant activity evaluation. The $1 \mathrm{ml}$ extraction solution mixed with $3 \mathrm{ml}$ $0.004 \%$ DPPH solution was placed in dark room for reacting $30 \mathrm{~min}$ at room temperature and then read the OD value at $517 \mathrm{~nm}$ from ultraviolet spectrophotometer. The anhydrous methanol was as blank. The DPPH radical scavenging rate was calculated by the relative change of $\mathrm{OD}$ value. 


\subsection{Data Analysis}

Each fermentation treatment was repeated 3 times and the significant variances of all treatments were check by Analysis of Variance (ANOVA) analysis ( $\mathrm{p} \leq$ $0.05)$. The experimental data were expressed as mean \pm standard error based on the ANOVA analysis. The significant difference for each treatment was analyzed by Duncan's New Multiple Range Test ( $\mathrm{p} \leq 0.05$ ) with the software of SPSS 16.0. The components of dandelion black tea were analyzed by Principal Component Analysis (PCA) with the software of LAV (Laboratory Analytical Viewer) and GC $\times$ IMS Library Search built in GC-IMS work station system.

\section{Results and Analysis}

\subsection{Effects of Fermentation on Sensory Evaluation of Dandelion Black Tea}

Results of sensory evaluation showed differences in the quality of dandelion black tea with different fermentation treatments (Table 2). Fermentation treatment 12 showed the best value in appearance, liquid color, aroma, taste and background color; the shape of the dandelion black tea was tight and not easy to disperse when brewing; liquid showed bright-orange character; the taste was mellow, full of fragrance without grass smell; the background color was red, soft and bright.

Table 2. Sensory evaluation results of dandelion black tea under different fermentation conditions.

\begin{tabular}{|c|c|c|c|c|c|c|}
\hline No. & Shape $(25 \%)$ & $\begin{array}{c}\text { Liquid color } \\
\quad(10 \%)\end{array}$ & Aroma (25\%) & Taste (30\%) & $\begin{array}{c}\text { Back color } \\
(10 \%)\end{array}$ & $\begin{array}{c}\text { Total score } \\
(100 \%)\end{array}$ \\
\hline 1 & 87 & 89 & 86 & 89 & 87 & 87.55 \\
\hline 2 & 85 & 87 & 84 & 89 & 90 & 86.65 \\
\hline 3 & 92 & 85 & 85 & 85 & 86 & 86.85 \\
\hline 4 & 87 & 85 & 92 & 88 & 90 & 88.65 \\
\hline 5 & 87 & 84 & 92 & 85 & 85 & 87.15 \\
\hline 6 & 88 & 92 & 85 & 90 & 90 & 88.45 \\
\hline 7 & 90 & 85 & 87 & 88 & 87 & 87.85 \\
\hline 8 & 89 & 89 & 90 & 87 & 88 & 88.55 \\
\hline 9 & 89 & 89 & 87 & 88 & 87 & 88 \\
\hline 10 & 88 & 88 & 87 & 88 & 88 & 87.75 \\
\hline 11 & 90 & 88 & 84 & 87 & 90 & 87.4 \\
\hline 12 & 87 & 92 & 90 & 92 & 91 & 90.15 \\
\hline 13 & 87 & 85 & 87 & 90 & 90 & 87.5 \\
\hline
\end{tabular}




\subsection{Effects of Fermentation on the Biochemical Components in Dandelion Black Tea}

The raw material of dandelion used in the current study contained chlorogenic acid $4.82 \mathrm{mg} / \mathrm{g}$ and caffeic acid $5.06 \mathrm{mg} / \mathrm{g}$ [1]. However, caffeic acid was not found and chlorogenic acid content decreased about 3 times after fermentation (Table 3). Nevertheless, treatment 12 still maintained good taste and had the highest chlorogenic acid content. Tea polyphenols are the main functional substances in black tea [4]. Results showed that content of tea polyphenols in fermentation treatment 12 and fermentation treatments 6 were significantly higher than other treatments, and the highest content was $1.4 \%$ in treatment 12 (Table 3). Tea water extract was an important index to reflect the strength and thickness of dandelion black tea soup, which was proportional to the concentration of tea soup [9] [10]. Results in the current study showed that water extracts of dandelion black tea with different fermentation treatments were obviously different, and the highest value was $32.59 \%$ in treatment 12 (Table 3); tea pigment is one of the important factors to reflect the sensory evaluation of dandelion black tea, and the liquid color of high-quality black tea should be orange and bright [11]. Thus, treatment 6 showed the highest absorbance of tea pigment, followed by fermentation treatment 12 . To sum up, fermentation treatment 12 and 6 showed high quality in sensory evaluation.

Table 3. Biochemical components of dandelion black tea under different fermentation conditions.

\begin{tabular}{|c|c|c|c|c|}
\hline No. & $\begin{array}{l}\text { Chlorogenic acid } \\
\qquad(\mathrm{mg} / \mathrm{g})\end{array}$ & Tea polyphenols (\%) & Tea pigment (OD) & Tea water extract $(\%)$ \\
\hline 1 & $1.27 \pm 0.14^{\mathrm{de}}$ & $0.77 \pm 0.07^{\mathrm{f}}$ & $0.32 \pm 0.01^{b}$ & $22.09 \pm 0.22^{\mathrm{g}}$ \\
\hline 2 & $1.1 \pm 0.23^{\mathrm{h}}$ & $0.78 \pm 0.09^{f}$ & $0.26 \pm 0.04^{\text {cde }}$ & $27.67 \pm 0.42^{c}$ \\
\hline 3 & $1.04 \pm 0.04^{\mathrm{i}}$ & $0.4 \pm 0.02^{\mathrm{g}}$ & $0.25 \pm 0.03^{\text {def }}$ & $26.14 \pm 0.62^{\mathrm{d}}$ \\
\hline 4 & $0.96 \pm 0.08^{j}$ & $1.09 \pm 0.05^{c}$ & $0.24 \pm 0.02^{\mathrm{def}}$ & $15.37 \pm 0.24^{\mathrm{k}}$ \\
\hline 5 & $1.2 \pm 0.06^{\mathrm{fg}}$ & $0.82 \pm 0.06^{\mathrm{ef}}$ & $0.2 \pm 0.03^{\mathrm{f}}$ & $26.1 \pm 0.31^{\mathrm{d}}$ \\
\hline 6 & $1.24 \pm 0.10^{\mathrm{ef}}$ & $1.4 \pm 0.07^{\mathrm{b}}$ & $0.48 \pm 0.02^{\mathrm{a}}$ & $29.15 \pm 0.32^{b}$ \\
\hline 7 & $1.15 \pm 0.01^{\mathrm{gh}}$ & $0.71 \pm 0.03^{f}$ & $0.23 \pm 0.01^{\mathrm{ef}}$ & $13.16 \pm 0.11^{j}$ \\
\hline 8 & $1.44 \pm 0.04^{\mathrm{b}}$ & $0.93 \pm 0.09^{\mathrm{de}}$ & $0.34 \pm 0.01^{\mathrm{b}}$ & $18.682 \pm 0.12^{1}$ \\
\hline 9 & $1.15 \pm 0.03^{\mathrm{gh}}$ & $1.01 \pm 0.08^{\mathrm{cd}}$ & $0.31 \pm 0.04^{\mathrm{bc}}$ & $24.07 \pm 0.27^{\mathrm{f}}$ \\
\hline 10 & $1.31 \pm 0.12^{\mathrm{cd}}$ & $0.84 \pm 0.09^{\text {ef }}$ & $0.29 \pm 0.05^{\mathrm{bcd}}$ & $12.28 \pm 0.01^{\mathrm{i}}$ \\
\hline 11 & $1.33 \pm 0.15^{c}$ & $0.72 \pm 0.08^{f}$ & $0.29 \pm 0.02^{\mathrm{bcd}}$ & $14.46 \pm 0.2^{\mathrm{h}}$ \\
\hline 12 & $1.53 \pm 0.07^{\mathrm{a}}$ & $1.54 \pm 0.09^{\mathrm{a}}$ & $0.45 \pm 0.02^{\mathrm{a}}$ & $32.59 \pm 0.31^{\mathrm{a}}$ \\
\hline 13 & $1.42 \pm 0.02^{\mathrm{b}}$ & $0.97 \pm 0.05^{\mathrm{d}}$ & $0.22 \pm 0.01^{\mathrm{ef}}$ & $24.69 \pm 0.21^{\mathrm{e}}$ \\
\hline
\end{tabular}

Different small letters in the same column showed significant differences among 13 treatments according to Duncan's New Multiple Range Test ( $\mathrm{p} \leq 0.05)$. 


\subsection{Effects of Fermentation on Aroma Components of Dandelion Black Tea}

The top view of aroma components (Figure 2) directly showed the differences of volatile aroma components among different treatments. Totally 17 kinds of alcohols, 14 kinds of aldehydes, 12 kinds of ketones, 6 kinds of esters, 6 kinds of organic acids and 5 kinds of sulfur compounds were detected. The aroma components were similar to those of traditional black tea [3] [11]. Traditional black tea was completely fermented tea, and its aroma came from volatile chemicals during the fermentation process, mainly including alcohols, esters, aldehydes, etc. [3]. In addition, more than 60 volatile substances that could not be identified were found in the current study, which needed further identification.

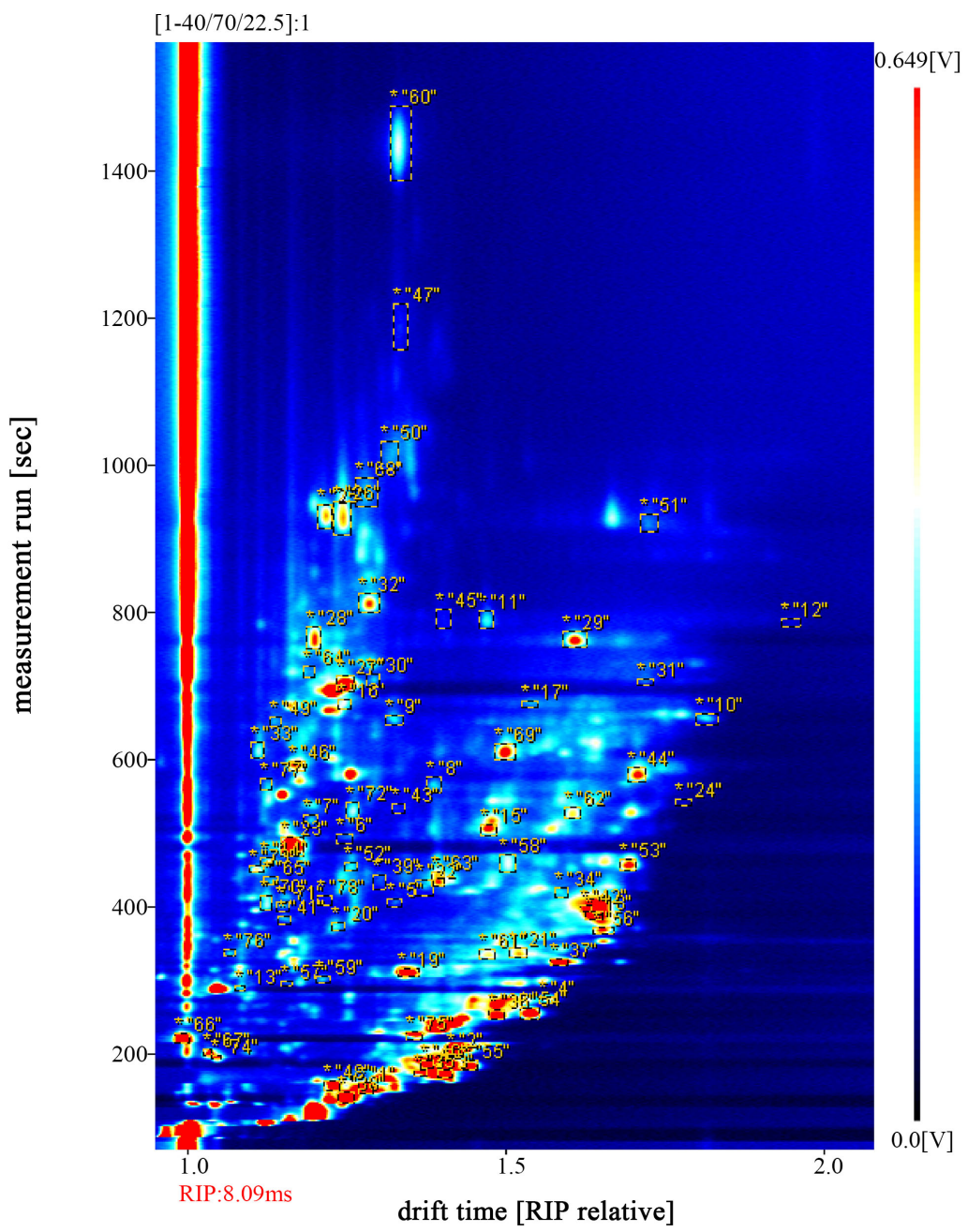

Figure 2. Gas chromatographic ion mobility spectrum of dandelion black tea. The figure was created by software of Laboratory Analytical Viewer based on the treatment 12; the $y$-axis was retention time; the $\mathrm{x}$-axis was drift time; the red vertical line represented the reaction ion peak (reaction ion peak, RIP, normalized drift time was $7.57 \mathrm{~ms}$ ); each point on either side of RIP represented a volatile organic compound; the content of the substance was represented by a color, and light blue represented a low content, red indicated high content. 
Principal Component Analysis (PCA) was used to analyze the above mentioned volatile compounds. Results showed that the main volatile compounds of treatments 4 and 7 were similar and the similarity was $85.3 \%$; the main volatile substances in treatment $1,3,4$ and 10 showed the greatest difference and their similarity was only $54.7 \%$. Results implied that fermentation treatment could change the type and quantity of volatile substances, thus affecting the sensory quality of dandelion black tea (Figure 3).

\subsection{Antioxidant Activity of Dandelion Black Tea under Different Fermentation Conditions}

The antioxidant function of dandelion black tea was tested and all dandelion black tea showed high antioxidant activity with DPPH free radical scavenging rate at least of $88 \%$ (Figure 4). Treatment 10 exhibited the highest free radical scavenging rate and not significant difference with treatment 4 and 12; however, DPPH free radical scavenging rate in the remaining treatments declined in different levels, indicating that fermentation process had a certain impact on the antioxidant activity of dandelion black tea.

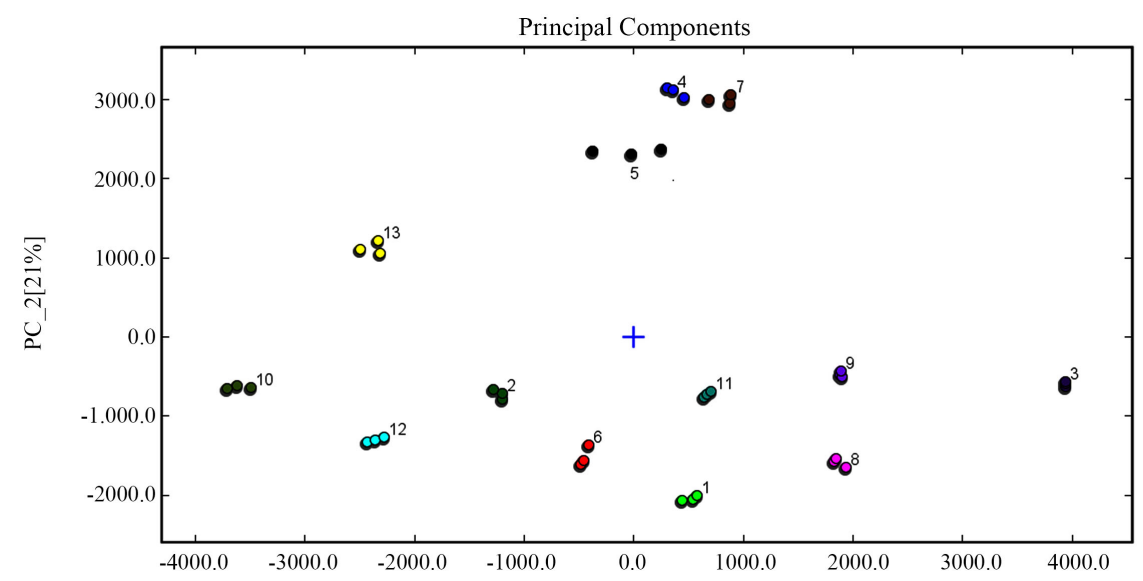

Figure 3. Principal component analysis of main volatile compounds for 13 dandelion black tea fermentation treatments.

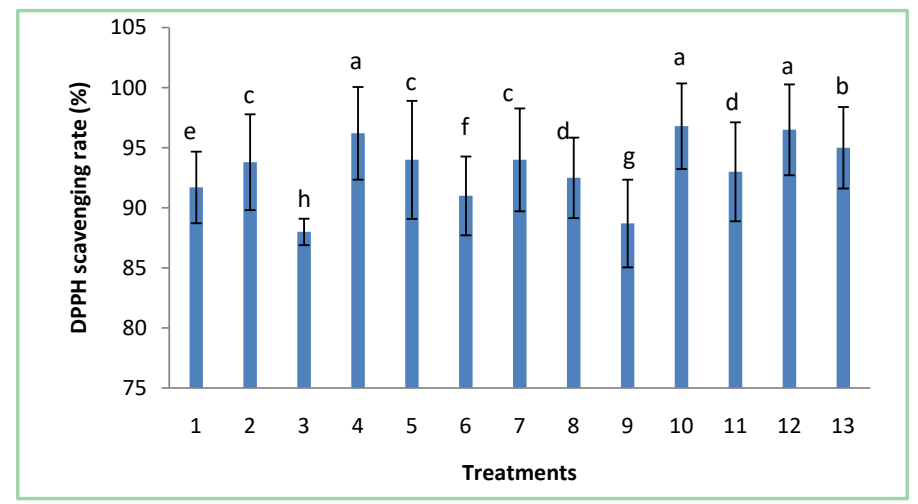

Figure 4. Antioxidant activity analysis of dandelion black tea. Different small letters showed significant differences among 13 treatments according to Duncan's New Multiple Range Test. 


\section{Discussions}

Phenolic acids such as caffeic acid and chlorogenic acid are the main functional components in dandelion [12]. The results showed that the phenolic acids of dandelion greatly decreased after fermentation, so that the content of caffeic acid could not be detected by HPLC, and the content of chlorogenic acid decreased more than three times. Caffeic acid produced total volatiles and the decrease of phenolic acids may relate to thermal degradation during fermentation [13]. According to the collation of the list of carcinogens published by the World Health Organization International Agency, caffeic acid was in the list of $2 \mathrm{~B}$ carcinogens, so the disappearance or decrease of caffeic acid was conducive to improving the safety of dandelion black tea. In addition, dandelion black tea had aromatic taste and no bitter taste from dandelion, which may because of the degradation of caffeic acid in the process of fermentation.

The main functional component of tea was tea polyphenols [4]. The content of polyphenols in traditional black tea ranged from $15 \%$ to $18 \%$, but the highest content of polyphenols in dandelion black tea in the current research was only $1.4 \%$, which may be the difference between the raw materials of dandelion black tea and traditional black tea, but the antioxidant activity of dandelion black tea had not been weakened, which may be related to the chlorogenic acid and other unknown functional substances still retained in black tea [14].

The aroma components of dandelion black tea were determined by gas ion mobility spectrometry (GIMS). The main volatile components of dandelion black tea were similar to those of traditional black tea, such as alcohols, aldehydes, ketones, etc. [7] [8]. In addition, more than 60 kinds of unknown volatile compounds in dandelion black tea were found, whether they were related to the unique functional activities of dandelion black tea remained to be further verified.

\section{Conclusion}

Through the sensory evaluation and biochemical component analysis of different fermentation technology of dandelion black tea, the optimal fermentation technology was as follows: fermentation temperature $25^{\circ} \mathrm{C}$, fermentation humidity $80 \%$, fermentation time $15 \mathrm{~h}$. Under this condition, the dandelion black tea showed a uniform and tight shape, bright-orange liquid, mellow taste and good quality as well as maintained a high antioxidant function activity.

\section{Acknowledgements}

This research was supported by the HAAFS Agriculture Science and Technology Innovation Project (2019-1-6-1); Hebei Key Research and Development Plan (19227126D) and (18227121D); Hebei Technology Innovation Guidance Project (19826902D).

\section{Conflicts of Interest}

The authors declare no conflicts of interest regarding the publication of this paper. 


\section{References}

[1] Wu, Z., Xue, Z., Li, H., Zhang, X., Wang, X. and Lu, X. (2019) Cultivation of Dandelion (Taraxacum erythropodium) on Coastal Saline Land Based on the Control of Salinity and Fertilizer. Folia Horticulturae, 31, 277-284.

https://doi.org/10.2478/fhort-2019-0022

[2] Gardner, E.J., Ruxton, C.H.S. and Leeds, A.R. (2007) Black Tea-Helpful or Harmful? A Review of the Evidence. European Journal of Clinical Nutrition, 61, 3-18. https://doi.org/10.1038/sj.ejcn.1602489

[3] Rawat, R., Gulati, A., Kiran Babu, G.D., Acharya, R., Kaul, V.K. and Singh, B. (2007) Characterization of Volatile Components of Kangra Orthodox Black Tea by Gas Chromatography-Mass Spectrometry. Food Chemistry, 105, 229-235. https://doi.org/10.1016/j.foodchem.2007.03.071

[4] Sun, B., Wang, W., He, Z., Zhang, M., Kong, F., Sain, M. and Ni, Y. (2018) Improvement of Stability of Tea Polyphenols: A Review. Current Pharmaceutical Design, 24, 3410-3423. https://doi.org/10.2174/1381612824666180810160321

[5] Tomlins, K.I. and Mashingaidze, A. (1997) Influence of Withering, Including Leaf Handling, on the Manufacturing and Quality of Black Teas-A Review. Food Chemistry, 60, 573-580. https://doi.org/10.1016/S0308-8146(97)00035-6

[6] Kim, M.H., Kim, S.D. and Kim, K.S. (2000) Effect of Salting Conditions on the Fermentation and Quality of Dandelion (Taraxacum platycarpum D.) Kimchi. Korean Journal of Food Science \& Technology, 32, 1142-1148.

[7] Zhao, M., Zhang, D.-L., Su, X.-Q., Duan, S.-M., Wan, J.-Q., Yuan, W.-X., Liu, B.-Y., Ma, Y. and Pan, Y.-H. (2015) An Integrated Metagenomics/Metaproteomics Investigation of the Microbial Communities and Enzymes in Solid-State Fermentation of Pu-erh Tea. Scientific Reports, 5, 10117. https://doi.org/10.1038/srep10117

[8] Lin, R., Rong, D., Xu, L. and Univercity, X.H. (2017) Feasibility Study of Green Tea Flavor Identification Based on GC-IMS Technology. Guangdong Chemical Industry, 44, 19-21.

[9] Chang, M.S. and Kim, G.H. (2015) Effects of a Combined Treatment of Hot Water with Green Tea Extract and $\mathrm{NaCl}$ on the Postharvest Quality of Fresh-Cut Burdocks. Korean Journal of Horticultural Science \& Technology, 33, 364-374. https://doi.org/10.7235/hort.2015.14042

[10] Zareef, M., Chen, Q., Ouyang, Q., Kutsanedzie, F., Hassan, M., Viswadevarayalu, A. and Wang, A. (2018) Prediction of Amino Acids, Caffeine, Theaflavins and Water Extract in Black Tea by FT-NIR Spectroscopy Coupled Chemometrics Algorithms. Analytical Methods, 10, 3023-3031. https://doi.org/10.1039/C8AY00731D

[11] Adnan, M., Ahmad, A., Ahmed, A., Khalid, N. and Ahmed, I. (2013) Chemical Composition and Sensory Evaluation of Tea (Camellia sinensis) Commercialized in Pakistan. Pakistan Journal of Botany, 45, 901-907.

[12] Rumalla, C.S., Avula, B., Wang, Y.H., Smillie, T.J. and Khan, I.A. (2011) Method Development and Identification of Taraxacum officinale Web. ex Wigg. Leaves and Roots Using HPTLC. Planta Medica, 77, 72. https://doi.org/10.1055/s-0031-1273601

[13] Moon, J.-K. and Shibamoto, T. (2010) Formation of Volatile Chemicals from Thermal Degradation of Less Volatile Coffee Components: Quinic Acid, Caffeic Acid, and Chlorogenic Acid. Journal of Agricultural and Food Chemistry, 58, 5465-5470. https://doi.org/10.1021/jf1005148

[14] Gomez, M.K., Singh, J., Acharya, P., Jayaprakasha, G.K. and Patil, B.S. (2018) Iden- 
tification and Quantification of Phytochemicals, Antioxidant Activity, and Bile Acid-Binding Capacity of Garnet Stem Dandelion (Taraxacum officinale). Journal of Food Science, 83, 1569-1578. https://doi.org/10.1111/1750-3841.14169 